\title{
On the Determinants of Exchange Rate Misalignments
}

\author{
Jamel Saadaoui* Jacques Mazier ${ }^{\dagger} \quad$ Nabil Aflouk ${ }^{\ddagger}$ \\ June 11, 2013
}

\begin{abstract}
The literature on exchange rate misalignments is very extensive as well as the literature on exchange rate determinants. To our knowledge, however, no study has analyzed the determinants of exchange rate misalignments. As huge capital inflows have been pouring into emerging countries since the climax of the crisis, exchange rate misalignments are becoming a crucial issue for policy makers. For a large panel of emerging and industrialized countries and on the period 1982-2008, we identify, empirically, the main determinants of exchange rate misalignments obtained thanks to a FEER approach (Williamson, 1994). Our analysis put forward trade openness, financial openness and regional specialization as determinant variables of exchange rate misalignments.
\end{abstract}

JEL Classification: F31, F32, O11.

Key words: Exchange Rate Misalignments, Trade Openness, Financial Openness, Regional Specialization.

${ }^{*} \mathrm{PhD}$ in Economics, University of Paris North.

${ }^{\dagger}$ Emeritus professor of Economics, University of Paris North.

${ }^{\ddagger} \mathrm{PhD}$ in Economics, University of Paris North. 


\section{Introduction}

As noted by Feldstein (2011), the return of risk appetite of investors, after the climax of the crisis in 2008, has leaded some emerging countries to reinstitute capital controls to stop the appreciation of their currencies because they fear the negative impact on growth of an increasingly overvalued currency.

These emerging countries experience a surge of capital inflows mainly because of favourable interest rate differentials with developed economies. This favourable interest rate differential is the outcome of economic policy lead by developed countries (mainly the United States) in order to sustain aggregate demand after the burst of the crisis in 2008.

In this general context, the objective of the paper is to analyse the main determinants of exchange rate misalignments (ERM, hereafter) obtained by a FEER approach Aflouk et al. (2010). The FEER is defined as the level of exchange rate which allows the economy to reach the internal and external equilibriums at the same time (Williamson, 1994). The internal equilibrium is defined as the full utilization of productive resources of a country without generating inflation pressures. The external equilibrium corresponds to a sustainable current account.

In a first step, using a model of world trade, FEERs are estimated for the main currencies (the dollar, the euro, the yen, the yuan and the pound sterling). In a second step, FEERs can be estimated for each emerging country, using simple national models and linking the estimation of national FEERs to the multinational model's results to get bilateral misalignments of each currency.

The literature on exchange rate misalignments is very extensive as well as the literature on exchange rate determinants. To our knowledge, however, no study has analyzed the determinants of exchange rate misalignments. As huge capital inflows have been pouring into emerging countries since the climax of the crisis, exchange rate misalignments are becoming a crucial issue for policy makers. For a large panel of emerging and industrialized countries and on the period 1982-2008, we identify, empirically, the main determinants of exchange rate misalignments obtained thanks to a FEER approach Williamson (1994). Our analysis put forward trade openness, financial openness and regional specialization as determinant variables of exchange rate misalignments. 
The remainder of the paper is organized as follows. Section 2 describes the main characteristics of the trade model used to estimate ERM. Section 3 identifies three variables which explain the ERM in the long run. Section 4 concludes.

\section{Trade Model}

\subsection{The multinational model}

The model describes the trade structure of the main countries or areas, namely, the United States, Japan, China, the Euro area, the United Kingdom and the Rest of the World using standard foreign trade equations: export and import volume equations, export and import price equations. Each country is successively treated as a residual and in that case export and import volumes are determined as residual of the equations of world trade equilibrium in value and in volume while their export and import prices are determined in the same manner as for other trading partners. We notice that this multinational specification gives a full account of interdependent effects in volume and prices of exports and imports of all countries. We incorporate a consumer prices equation to take into account the feedback effect between the consumer prices and the import prices. The real effective exchange rate is defined relatively to the consumption prices. Finally, the current account is defined as the trade balance augmented of debt service.

In this framework, the FEERs are defined as the real effective exchange rates compatible with the simultaneous realization of the internal and external equilibriums at medium term of each trading partner. The internal equilibrium means that actual output follows the potential output and the external equilibrium means that actual current account corresponds to the sustainable current account at medium term 1 .

On the whole, each multinational model comprises 35 endogenous variables $(x$,

\footnotetext{
${ }^{1}$ See Jeong et al. (2010). The methodology used is a synthesis of previous works on the FEER (Borowski and Couharde (2003); Jeong and Mazier (2003)) and of the Symmetric Matrix Inversion Method (SMIM) recently proposed by Cline (2008). The external equilibrium is obtained thanks to econometrics estimates of structural current account balances (Lee et al. (2008)). The internal equilibrium is defined as the state of full utilization of productive resources, without inflation pressures. For sake of simplification, a restrictive approach, limited to the measure of the potential output, is adopted.
} 
$m, p x, p m, p d$ for the six countries or areas and the five bilateral exchange rates e) for 35 equations $(x, m, b$ for the five countries other than the residual one, $p x$, $p m, p d$ for the six countries and the two world trade equilibrium equations). The real effective exchange rates are calculated expost using bilateral exchange rates and consumer prices.

\subsection{The national model}

For each emerging country (Korea, Brazil, India, Mexico, Argentina, Chile, Colombia, Indonesia, Malaysia, Philippines, Thailand and Uruguay), except China, it is possible to estimate an equilibrium exchange rate using a foreign trade model in which the world demand and the world trade prices are exogenous. It is not necessary for a relatively small country at the world scale to use a multinational model to estimate equilibrium exchange rates (Jeong and Mazier, 2003). The equations specify the trade volume and price equations for a small country facing world economy. Solving this simplified model in logarithmic differential form gives $r$, the misalignment in real effective terms:

$$
r_{i}=\left[\frac{\left(\left(b_{i} /\left[\mu_{i} T_{i}\left(1-\sigma_{p e t x i}-\sigma_{x i}\right)\right]\right)+\eta m_{i} d i_{i}-\eta x_{i} d_{i}^{*}\right)}{\left(\left(1-\alpha x_{i}\right) \varepsilon x_{i}+\varepsilon m_{i} \alpha m_{i}+\alpha x_{i}-\alpha m_{i}\right)}\right]
$$

Where $b$ is the difference between the observed current account and the equilibrium one, as percentage of GDP, $d^{*}$ is the world demand in volume and $d i$ is the internal demand in volume, written in logarithmic differential compared with the equilibrium, $\sigma_{\text {petx }}=E P_{\text {pet }} M_{\text {pet }} / P X X$ is the ratio of net oil imports on non-oil exports and $\sigma_{x}=i E F / P X X$ is the ratio of foreign debt service on non-oil exports, $\mu$ the openness ratio and $T$ the ratio of export to import. The FEER approach focuses on the real effective exchange rates. However, the nominal bilateral exchange rate against the dollar of each currency can be more intelligible. We can find out $e$, the degree of misalignment in bilateral nominal term as we can see in equation (2) and $r c$, the effective ERM based on consumer prices as shown in equation (3); the partner countries' misalignments are given by the previous multinational model:

$$
e_{i}=r_{i}-\sum_{j \neq i} \lambda_{i j}\left(p x_{j}-e_{j}\right)
$$




$$
r c_{i}=\left(1-\alpha m_{i} \mu_{i}\right) r_{i}+\sum_{j \neq i} \nu_{i j}\left(p d_{j}-e_{j}\right)-\sum_{j \neq i} \lambda_{i j}\left(p x_{j}-e_{j}\right)
$$

Where $p x$ is the global export price and $p d$ is the consumer price.

\section{Determinants of ERM}

In order to identify the main determinants of ERM for a large panel of industrialized and emerging countries on the period 1982-2008, firstly, we test the presence of unit root in the series of ERM and its explanatory variables. Secondly, we test the existence of a long run relationship between ERM and its determinants thanks to cointegration tests. Thirdly, we proceed to the empirical estimation thank to the Pooled Mean Group (PMG) estimator introduced by Pesaran et al. (1999).

\subsection{Panel unit root tests}

In this sub-section, we implement various unit root tests in order to determine the order of integration of the absolute value of the ERM (aerm) and its explanatory variables, namely, the trade openness ratio (open) measured as the half-sum of export and import in percentage of GDP, the relative financial openness indicator (rkaopen) based on a de jure measure of capital account openness (the ChinnIto index, 2008) and the regional specialization indicator ( $\mathrm{xreg}$ ) measured as the share of exports towards the regional area (East Asia, South America and North America) in percentage of total exports.

As we can see in Table 1, all the series are nonstationary I(1) series except aerm. As a series is $\mathrm{I}(1)$ if it achieves stationarity after first differencing. The series of ERM measured in absolute value, aerm, is a stationary series. This result is not surprising since this variable is a linear combination of two nonstationary series ${ }^{2}$. As shown by Saadaoui (2011a), the real effective exchange rates (reer) and the fundamental equilibrium exchange rate (feer) are integrated and cointegrated. These results are confirmed by the CADF test introduced by Pesaran (2007) by

\footnotetext{
${ }^{2}$ The aerm variable is equal to the difference between the natural logarithm of the reer and the natural logarithm of the feer in absolute value.
} 
Table 1: Panel unit roots tests

\begin{tabular}{lrrrr}
\hline Test & $L L C$ & Breit. & $F_{-} A D F$ & $F_{-} P P$ \\
\hline Difference & $\mathrm{No}$ & $\mathrm{No}$ & $\mathrm{No}$ & $\mathrm{No}$ \\
Exo. var. & $\mathrm{C}, \mathrm{T}$ & $\mathrm{C}, \mathrm{T}$ & $\mathrm{C}, \mathrm{T}$ & $\mathrm{C}, \mathrm{T}$ \\
Null Hyp. & $\mathrm{UR}$ & $\mathrm{UR}$ & $\mathrm{UR}$ & $\mathrm{UR}$ \\
Common UR & $\mathrm{Yes}$ & $\mathrm{Yes}$ & $\mathrm{No}$ & $\mathrm{No}$ \\
aerm & $-9.39^{* * *}$ & $-2.32^{* *}$ & $140.08^{* * *}$ & $153.63^{* * *}$ \\
open & 1.94 & 3.68 & 22.80 & 20.23 \\
rkaopen & 1.98 & -1.19 & 32.94 & 33.20 \\
xreg & 1.37 & $-1.51^{*}$ & 25.66 & 24.21 \\
\hline
\end{tabular}

Note: "UR" indicates the null hypothesis of the presence of unit root. The symbol ***, ** indicates statistical stationarity at the 1 percent and 5 percent level, respectively. The table shows different panel unit root tests: Levin et al. (2002) (LLC); Breitung (2000); Maddala and Wu (1999) and Choi (2001) Fisher-type panel unit root tests (F_ADF and F_PP). Source: authors's calculations.

subtracting cross section averages of lagged levels in addition to the standard ADF equation; this test is robust to cross section dependencies (see appendix A).

\subsection{Cointegration tests}

The next step will consist to test if there is a long run relationship between the absolute value of the ERM and its determinants (that is the residuals are stationary). If a long run relationship exists then we can estimate this long run relationship thanks to the Pooled Mean Group (PMG) estimator introduced by Pesaran et al. (1999).

As we can see in Table 2, the results of Pedroni's cointegration tests (1999) indicate clearly that the aerm variable is cointegrated with its determinants at the 1 per cent level. These results are confirmed by the Westerlund's cointegration tests (2007). In these tests, the existence of a negative and significant error correction term is taken as proof for cointegration. In case of cross section dependencies between members of the panel, critical values need to be obtained through bootstrapping (see appendix B). 
Table 2: Panel cointegration tests

\begin{tabular}{lr}
\hline \multicolumn{2}{c}{ Pedroni residual cointegration tests (1999) } \\
\hline \multicolumn{2}{c}{ Null Hypothesis: No cointegration } \\
\hline $\begin{array}{lr}\text { Included observations } \\
\text { Cross-sections included }\end{array}$ & 459 \\
\hline \multicolumn{1}{c}{ Alternative hypothesis: common AR coefficients (within-dimension) } & -1.20 \\
\hline Panel-v & $-2.34^{* * *}$ \\
Panel-rho & $-7.89^{* * *}$ \\
Panel-PP & $-7.87^{* * *}$ \\
Panel-ADF & -0.97 \\
\hline \multicolumn{1}{c}{ Alternative hypothesis: individual AR coefficients (between-dimension) } \\
\hline Group rho-Statistic & $-11.26^{* * *}$ \\
Group PP-Statistic & $-9.23^{* * *}$ \\
Group ADF-Statistic
\end{tabular}

Note: the symbol ${ }^{* * *}$ indicates statistical significance at the 1 per cent level. ${ }^{* * *}$ Reject null of nonstationary even at the $1 \%$ level. Source: authors' calculations.

\subsection{Estimation results}

As the variables are cointegrated, we can estimate the long relationship thanks to the PMG estimator. Since the PMG estimator imposes long-run coefficients to be constant for all individuals, while it allows short run heterogeneity, the error correction model associated with the $\operatorname{ARDL}(1,1,1,1)$ specification yields 3 .

$$
\begin{gathered}
\Delta \text { aerm }_{i, t}=\phi\left(\text { aerm }_{i, t-1}-\theta_{0}-\theta_{1} \text { open }_{i, t}-\theta_{2} \text { rkaopen }_{i, t}-\theta_{3} \text { xreg }_{i, t}\right) \\
-\delta_{2 i} \text { open }_{i, t}-\delta_{4 i} \Delta \text { rkaopen }_{i, t}-\delta_{6 i} \Delta \text { xreg }_{i, t}+\varepsilon_{i, t}
\end{gathered}
$$

As we can see in table 3, all the variables are significant and correctly signed. Higher trade openness (open increases) increases the impact of a variation of price competitiveness on current account. Consequently, a smaller variation of exchange

\footnotetext{
${ }^{3}$ ARDL means Autoregressive Distributed Lag.
} 
rate is necessary to reach the external equilibrium, which implies smaller misalignments. Stronger regional ( $x r e g$ increases) integration implies more price competition, which limits misalignments. Higher financial openness (rkaopen increases) facilitates monetary adjustments, which reduces exchange rates misalignments, while capital controls have the opposite effect. A negative relation is therefore expected between the financial openness indicator and misalignment. The Hausman test confirms the long run homogeneity of the coefficients.

Table 3: Long run determinants of ERM

\begin{tabular}{lcr}
\hline PMG & Long-run coefficient $(\theta)$ & $p$-value \\
\hline open & $-0.311^{* * *}$ & 0.000 \\
rkaopen & $-0.022^{* * *}$ & 0.005 \\
xreg & $-0.331^{* * *}$ & 0.001 \\
\hline Error-correction term $(\theta)$ & $-0.578^{* * *}$ & 0.000 \\
\hline Hausman test & 2.740 & 0.430 \\
\hline Number of cross-section & 17 & \\
Number of periods & 26 & \\
Number of observations & 442 & \\
\hline
\end{tabular}

Note: the acronym PMG stands for the Pooled Mean Group estimator. The symbol *** indicates statistical significance at the 1 per cent level. The null hypothesis in the Hausman test is homogeneity of the long run coefficient in the PMG estimation. Source: authors' calculations.

\section{Conclusion}

In a context of increasing movements of capital flows observed since the climax of the crisis (especially capital inflows towards emerging countries), the objective of the paper was to analyse the main determinants of ERM obtained by a FEER approach.

For a large panel of emerging and industrialized countries and on the period 1982-2008, we identify, empirically, the main determinants of ERM. Our analysis put forward trade openness, financial openness and regional specialization as 
determinant variables of ERM.

Our results show that a reduction of misalignments could be obtained by gradual increase of capital account openness especially for South East Asian countries that run large undervaluation as the trade openness ratio and regional specialization are more structural variables. These results are consistent with those of Saadaoui (2011b) in which a gradual openness of capital account should help to reduce the large current account surpluses of South-East Asian countries in the medium run (through upward pressures on domestic investment rates).

\section{References}

Aflouk, N., S.-E. Jeong, J. Mazier, and J. Saadaoui (2010). Exchange rate misalignments and international imbalances: a FEER approach for emerging countries. Économie Internationale 124(4), 31-74.

Borowski, D. and C. Couharde (2003). The exchange rate macroeconomic balance approach: New methodology and results for the euro, the dollar, the yen and the pound sterling. Open Economies Review 14(2), 169-190.

Breitung, J. (2000). The local power of some unit root tests for panel data. In Advances in Econometrics, Vol. 15: Nonstationary Panels, Panel Cointegration, and Dynamic Panels, pp. 161-178. JAI Press.

Choi, I. (2001). Unit root tests for panel data. Journal of International Money and Finance 20(2), 249-272.

Cline, W. R. (2008). Estimating consistent fundamental equilibrium exchange rates. PIIE Working Paper 08-6.

Feldstein, M. S. (2011). The role of currency realignments in eliminating the US and China current account imbalances. NBER Working Paper 16674.

Jeong, S.-E. and J. Mazier (2003). Exchange rate regimes and equilibrium exchange rates in East Asia. Revue économique 54(5), 1161-1182. 
Jeong, S.-E., J. Mazier, and J. Saadaoui (2010). Exchange rate misalignments at world and European levels: a FEER approach. Économie Internationale 121(3), $25-58$.

Lee, J., G. M. Milesi-Ferretti, J. D. Ostry, A. Prati, and L. A. Ricci (2008). Exchange rate assessments: CGER methodologies.

Levin, A., C.-F. Lin, and C.-S. J. Chu (2002). Unit root tests in panel data: asymptotic and finite-sample properties. Journal of Econometrics 108(1), 1-24.

Maddala, G. S. and S. Wu (1999). A comparative study of unit root tests with panel data and a new simple test. Oxford Bulletin of Economics and Statistics 61(S1), 631-652.

Pedroni, P. (1999). Critical values for cointegration tests in heterogeneous panels with multiple regressors. Oxford Bulletin of Economics and Statistics 61(S1), 653-670.

Persyn, D. and J. Westerlund (2008). Error-correction based cointegration tests for panel data. Stata Journal 8(2), 232-241.

Pesaran, M. H. (2007). A simple panel unit root test in the presence of cross-section dependence. Journal of Applied Econometrics 22(2), 265-312.

Pesaran, M. H., Y. Shin, and R. P. Smith (1999). Pooled mean group estimation of dynamic heterogeneous panels. Journal of the American Statistical Association $94(446), 621-634$.

Saadaoui, J. (2011a). Exchange rate dynamics and fundamental equilibrium exchange rates. Economics Bulletin 31(3), 1993-2005.

Saadaoui, J. (2011b). Global imbalances and capital account openness: an empirical analysis. CEPN Working Paper 2011-18.

Westerlund, J. (2007). Testing for error correction in panel data. Oxford Bulletin of Economics and Statistics 69(6), 709-748. 
Williamson, J. (1983). The Exchange Rate System. Institute for International Economics.

Williamson, J. (1994). Estimating Equilibrium Exchange Rates. Peterson Institute Press. Peterson Institute for International Economics. 


\section{A Panel unit root tests}

Table A.1: Integration of the variables

\begin{tabular}{lll}
\hline & Level & First Difference \\
\hline \multirow{2}{*}{ aerm } & $-2.670^{* * *}$ & $-11.670^{* * *}$ \\
& $(0.004)$ & $(0.000)$ \\
\hline \multirow{2}{*}{ open } & 3.528 & $-5.059^{* * *}$ \\
& $(1.000)$ & $(0.000)$ \\
\multirow{2}{*}{ rkaopen } & 2.807 & $-4.604^{* * *}$ \\
& $(0.997)$ & $(0.000)$ \\
\multirow{2}{*}{ xreg } & -0.257 & $-6.220^{* * *}$ \\
& $(0.398)$ & $(0.000)$ \\
\hline
\end{tabular}

Notes: The p-values are in parentheses. The symbol ${ }^{* * *}$ indicates statistical stationarity at the 1 per cent level. Source: authors' calculations.

\section{B Cointegration of the involved variables}

Table B.1: Cointegration of the variables

\begin{tabular}{lllll}
\hline & $G \tau$ & $G \alpha$ & $P \tau$ & $P \alpha$ \\
\hline \multirow{2}{*}{ aerm, open, rkaopen, xreg } & $-7.863^{* * *}$ & $-3.334^{* * *}$ & $-5.398^{* * *}$ & $-4.809^{* * *}$ \\
& $(0.000)$ & $(0.000)$ & $(0.000)$ & $(0.000)$ \\
\hline
\end{tabular}

Notes: The symbol ${ }^{* * *}$ indicates statistical significance at the 1 per cent level. The p-value for cointegration tests are based on bootstrap methods, where 800 replications are used. See Persyn and Westerlund (2008) for the details. Source: authors' calculations. 


\title{
C Source of the involved variables
}

\author{
Table C.1: Data source
}

\begin{tabular}{ll}
\hline Variable & Source \\
\hline $\begin{array}{l}\text { xreg, open } \\
\text { rkaopen }\end{array}$ & CHELEM, CEPII's Database, 2009, 2010. \\
\hline
\end{tabular}

